\title{
Plant wax alkanes and alcohols as herbivore diet composition markers
}

\author{
MIGUEL N. BUGALHO, HUGH DOVE, WALTER KELMAN, JEFF T. WOOD, AND ROBERT W. MAYES
}

\begin{abstract}
Bugalho is a post-doctoral Research Fellow at Centro de Ecologia Aplicada, Instituto Superior de Agronomia, 1349-017 Tapada da Ajuda, Lisboa, Portugal; Dove and Kelman are Senior Researchers at CSIRO Plant Industry, GPO Box 1600, Canberra, ACT 2601, Australia; Wood is a statistician who was at CSIRO Mathematical and Information Sciences, GPO Box 664, Canberra, ACT 2601, Australia during the work and presently is at the Statistical Consulting Unit, John Dedman Building, Australian National University, ACT 0200, Australia; Mayes is a Senior Researcher at The Macaulay Institute, Craigiebuckler, Aberdeen $A B 158 Q H$, Scotland.
\end{abstract}

Abstract

The $n$-alkanes in plant cuticular wax have been used as markers for estimating the species composition of herbivore diets, but the long-chain fatty alcohols $(\mathrm{LCOH})$ of plant wax may also be useful. The objective of this research was to assess if $\mathrm{LCOH}$ contributed extra information to differentiate plant species, compared with n-alkanes only. We used 3 data sets consisting of $n$ alkane and $\mathrm{LCOH}$ concentrations of plant species occurring in pastures of New South Wales, Australia. We used Principal Component Analysis (PCA) to summarise the data for n-alkane and $\mathrm{LCOH}$ concentrations obtained for the species in these data sets. The first 3 principal components explained 86 to $93 \%$ and 75 to $99 \%$ of the variance in n-alkane and $\mathrm{LCOH}$ concentrations, respectively. Orthogonal Procrustes Rotation (OPR) was then used to compare the results of PCA conducted with n-alkane and $\mathrm{LCOH}$ data, with a view to establishing whether $\mathrm{LCOH}$ provided discriminatory information in addition to that provided by the $n$ alkanes. Results of OPR indicated that this was so for all 3 data sets, and suggested that the $\mathrm{LCOH}$ would be useful additional markers for discriminating between plant species. We tested this by using Discriminant Analysis and cross-validation procedures in 2 data sets to distinguish between defined species groups of $\mathbf{C}_{3}$ grasses, $\mathrm{C}_{4}$ grasses, clovers and Lotus spp. The discrimination between these categories and the proportion of plant species correctly classified into the defined categories was better when using n-alkanes and LCOH together, compared with alkanes alone. Our results indicate that $\mathrm{LCOH}$ provided additional information that could be used for distinguishing plant species as part of estimating the species composition of herbivore diets.

Key Words: n-alkanes, long-chain fatty alcohols, markers, diet composition, herbivores

The species composition of herbivore diets can be estimated by exploiting differences among plant species in their cuticular wax compounds, especially n-alkanes (Dove and Mayes 1991). The nalkanes are relatively inert, long-chain saturated hydrocarbons

Miguel Bugalho thanks the Portuguese Ministry of Science and Technology (Postdoctoral grant FCT/SFRH/727/2000) and CSIRO Plant Industry, Australia, for support during a period as Visiting Scientist at CSIRO. We thank Denys Garden and David Officer of NSW Agriculture, Australia, for the provision of the herbage samples in data sets 2 and 3, respectively. We also thank Stuart Lamb and Susan Hoebee for their assistance with the $\mathrm{n}$-alkane and $\mathrm{LCOH}$ analyses and Christine Donnelly for the preparation of Figures 1 to 3 .

Manuscript accepted 17 Aug. 03.

\section{Resumen}

Los n-alcanos de la cera cuticular de las plantas han sido usados como marcadores para determinar la composición de especies en las dietas de los herbívoros, pero los alcoholes grasos de cadena larga ( $\mathrm{LCOH}$ ) también pueden ser útiles. El objetivo de esta investigación fue evaluar si los $\mathrm{LCOH}$ aportan información extra para diferenciar las especies de plantas, comparados con los n-alcanos solos. Usamos 3 juegos de datos consistentes de concentraciones de n-alcanos y LCOH de especies de plantas que están presentes en los potreros de Nueva Gales del Sur, Australia. Usamos el análisis de componentes principales (PCA) para resumir los datos de las concentraciones de $\mathbf{n}$-alcanos y LCOH obtenidos para las especies de plantas de los juegos de datos utilizados. Los tres primeros componentes principales explicaron del 86 al $93 \%$ y del 75 al $99 \%$ de la variación en las concentraciones de n-alcanos y $\mathrm{LCOH}$ respectivamente. Entonces se uso la Rotación de Procrustes Ortogonales (OPR) para comparar los resultados de los componentes principales realizados con los datos de n-alcanos y $\mathrm{LCOH}$, con la mira de establecer si los LCOH proveyeron información discriminatoria adicional a la proporcionada por los n-alcanos. Los resultados de OPR indicaron que esto si fue así para los $\mathbf{3}$ juegos de datos y sugirieron que los LCOH pudieran ser marcadores adicionales útiles para discriminar entre especies de plantas. Probamos esto usando procedimientos de Análisis Discriminante y validación cruzada en dos juegos de datos para distinguir entre grupos de especies definidas de zacates $\mathbf{C}_{3}$, zacates, $\mathbf{C}_{4}$, tréboles y Lotus spp. La discriminación entre estas categorías y la proporción de especies de plantas correctamente clasificadas dentro de las categorías definidas fue mejor cuando se uso n-alcanos y LCOH juntos en comparación con los alcanos solos. Nuestros resultados indican que LCOH proveyeron información adicional que pudiera ser utilizada para distinguir especies de plantas como parte de la estimación de la composición de especies de las dietas de los herbívoros.

(C21 to $\mathrm{C} 37$ ) that, in ruminants, can be recovered in feces to a degree dependent on their carbon-chain length (Dove and Mayes 1991, 1996). Diet composition is estimated by relating the n-alkane content of feces to the $n$-alkane content of the plants available to herbivores, after correcting for n-alkane fecal recovery (e.g. Dove and Moore 1995). Using plant wax n-alkanes or other wax components as diet markers offers several advantages over other nutritional markers (Dove and Mayes 1999, Mayes and Dove 2000, Sandberg et al. 2000). An important constraint, however, is 
that the number of species that can be differentiated in the diet cannot exceed the number of alkane markers available; this limits differentiation to usually lower than 15 species (Mayes and Dove 2000). When dealing with complex plant communities such as rangelands, the number of plant species available to the herbivore may thus exceed the number of n-alkane markers available. One means of overcoming this constraint is to include more classes of plant wax components as markers for discriminating between plant species. A prerequisite of this approach is that the additional markers must provide discriminatory information additional to that provided by the $n$-alkanes.

Long-chain fatty alcohols $(\mathrm{LCOH})$ are widespread in the plant species consumed by herbivores and frequently occur at higher concentrations than n-alkanes (Kolattukudy 1976, Dove and Mayes 1999, Mayes and Dove 2000, Kelman et al.2003). Furthermore, the LCOH can be separated and quantified by an extension (unpublished data, R.W. Mayes) of the existing procedure used to analyse n-alkanes. This suggests that $\mathrm{LCOH}$ could be useful diet composition markers in addition to the n-alkanes.

Our objectives in the present study were:

1. To quantify n-alkane and $\mathrm{LCOH}$ concentrations in the cuticular wax of pasture species commonly found in New South Wales, Australia;

2. To assess if the $\mathrm{LCOH}$ provided additional discriminatory information, compared with n-alkanes alone, to distinguish between plant species;

3. To compare the effectiveness of using n-alkanes alone or in combination with $\mathrm{LCOH}$, to describe and differentiate between species or defined groupings of plant species.

\section{Methods}

\section{Plant data sets}

Three sets of samples were used to obtain information on the n-alkane and long-chain fatty alcohol (LCOH) content of plant species commonly found in a variety of pastures in Australia. Samples were collected at: Ginninderra Experiment Station, Australian Capital Territory, latitude $35^{\circ} 12^{\prime} \mathrm{S}$, longitude $149^{\circ} 12^{\prime} \mathrm{E}$ (Data set 1); near Goulburn, New South Wales, latitude $34^{\circ} 39^{\prime} \mathrm{S}$, longitude $149^{\circ} 31^{\prime} \mathrm{E}$ (Data set 2) and near Grafton, New South Wales, latitude $29^{\circ} 37^{\prime} \mathrm{S}$, longitude $152^{\circ}$
57' E (Data set 3). Differences in the method of sample collection and the nature of the material collected suggest that these may be regarded as 3 independent data sets, although combinations of data sets were also examined to explore the trends in between-species differences in the patterns of alkane or $\mathrm{LCOH}$ concentrations.

Data set 1 consisted of shoot material from 5 grass species (Austrodanthonia richardsonii (Cashmore) H.P. Linder cv. Taranna, Phalaris aquatica L., Vulpia myuros (L.) Gmel., Bromus catharticus Vahl. and Festuca arundinacea Schreb.) and 7 legumes (Trifolium striatum L., T. glomeratum L., T. repens L., Lotus corniculatus L. "Prostrate", L. corniculatus L. cv. Goldie, L. pedunculatus Cav. cv. Sharnae, L. pedunculatus Cav. cv. Grasslands Maku). Individual plants of each species were cut from a grazed sward (Kelman et al. 2003) using electric clippers, and were then composited within species to provide sufficient material for plant wax analyses.

The second data set consisted of leaf tissue from 7 grass species (Austrodanthonia racemosa (R. Br.) H.P. Linder, A. pilosa (R. Br.) H.P. Linder, Elymus scaber (R. Br.) A. Love, Bothriochloa macra (Steud.) S.T. Blake, Chloris gayana Kunth, Themeda australis (R. Br.) Stapf., Microlaena stipoides (Labill.) R. Br.) with the last species coming from 2 sampling locations at the site (designated Microlaena stipoides 1 and 2). The leaf tissue was obtained by hand separation of material harvested from a sward of spaced plants (Norton et al. 2001), using an electric sheep-shearing handpiece.

The third data set consisted of shoot material of 10 tropical grasses (Paspalum notatum Flugge, Paspalum dilatatum Flugge, Axonopus fissifolius (Raddi) Kulhm, Imperata cylindrica (Nees) C.E.Hubbard, Setaria anceps Stapff ex Massey, Pennisetum clandestinum Hoscht. ex Chiov., Cynodon dactylon (L.) Pers., Digitaria didactyla (Willd.), Chloris gayana Kunth, Sporobolus indicus (Buse) Baijens var. major) similarly harvested from pastures in sub-tropical northern New South Wales, Australia, within a larger study of the biology of the weed species Sporobolus indicus var. major (see Hoebee et al. 1998).

Following collection, all plant samples were stored at $-18^{\circ} \mathrm{C}$, before being freeze-dried and ground ( $1 \mathrm{~mm}$ screen) for $\mathrm{n}$-alkane and $\mathrm{LCOH}$ analysis.

\section{$\mathrm{N}$-alkane and LCOH extraction and quantification}

The n-alkanes in data sets 1 and 2 were extracted and quantified as described by Mayes et al. (1986), with modifications indicated by Salt et al. (1992); internal standards used were docosane (C22 alkane) and tetratriacontane (C34 alkane). In addition, 1-pentacosanol (C25 normal alcohol) was used as an internal standard to quantify the LCOH. It should be noted that the alkaline extraction conditions used for the n-alkanes (Mayes et al. 1986) extract not only the free $\mathrm{LCOH}$ of cuticular wax, but also the $\mathrm{LCOH}$ bound as wax esters. Extracted LCOH were eluted from silica gel columns using 1:1 heptane:ethanol immediately following alkane elution. The $\mathrm{LCOH}$ eluates were dried, redissolved in $1: 1$ heptane:ethanol and injected into a $30 \mathrm{~m}$ x $0.53 \mathrm{~mm}$ ID BPX35 bonded-phase silica column $(0.5 \mathrm{~mm}$ film thickness; SGE Pty Ltd Australia) in a PU4550 gas chromatograph fitted with a splitless injector and flame ionization detector. The carrier gas was helium.

Because of difficulties encountered in separating alcohols from sterols under the chromatography conditions used, it is possible that the compounds described as 1-C27 OL and 1-C29-OL could in fact be sterols. However, as this does not affect subsequen data analysis or the arguments presented in this paper, these components are assumed hereafter to be primary alcohols.

Essentially the same methods were used to extract and quantify the alkanes and $\mathrm{LCOH}$ in data set 3 except that $\mathrm{C} 24$ alkane (tetracosane) was used as the first internal standard for alkanes. Both n-alkanes and $\mathrm{LCOH}$ were quantified through a $15 \mathrm{~m} \times 0.53 \mathrm{~mm}$ DB 1 column fitted in a Varian 3400 gas chromatograph, using helium as the carrier gas and flame ionization detection.

\section{Statistical analysis}

The n-alkane and LCOH analyses were based on bulk samples of individual plant species, and thus do not provide an estimate of the variability in the concentration of these compounds between individual plants or plant parts, within a species. However, as we describe in more detail below, earlier studies with similar plant species suggest that most of the variance in alkane or $\mathrm{LCOH}$ concentration can be ascribed to plant species (e.g. Dove et al. 1996, Mayes and Dove 2000).

Alkanes C21 to C24 were excluded from the statistical analyses because their estimated concentrations were very low and of the same order of magnitude as the analytical error (3 to $4 \mathrm{ppm}$ ). Alkane C35 
was excluded from the statistical analyses of data set 1 , for the same reason. Similarly, in data set 3 (Table 2) data were available only for the even-chain $\mathrm{LCOH}$ between $\mathrm{C} 24 \mathrm{OH}$ and $\mathrm{C} 30 \mathrm{OH}$. Before statistical analysis, concentrations of $\mathrm{n}$-alkanes and $\mathrm{LCOH}$ in each data set were normalized by $\log$ transformation $(\log (x+1))$, to accommodate the fact that the untransformed concentrations of the 2 classes of compound differed by orders of magnitude.

Principal Component Analyses (PCA; GENSTAT, Lawes Agricultural Trust) were used to summarize the information on the pattern of alkane or $\mathrm{LCOH}$ concentrations within a data set or combinations of data sets. The overall significance of principal components of a given dimension was assessed using chi-square tests and where required, mean PCA scores for groups of species were compared by analysis of variance. Most of the original variability in the pattern of marker content in a plant species could be reduced to the first 2 to 3 principal components (PC1 to $\mathrm{PC} 3$ ).

For each data set, 2 PCA outputs were obtained, one based on the n-alkane content and the other based on the long-chain fatty alcohols $(\mathrm{LCOH})$ content of the plant species in the set. These pairs of PCA outputs were then compared by Orthogonal Procrustes Rotation (OPR) to assess if the 2 classes of marker had simply identified the same variation, or whether the $\mathrm{LCOH}$ provided extra information of potential use for differentiating plant species. To achieve this, OPR rotates the axes of each PCA output in an attempt to minimize the residual sum of squares between the PCA scores based on n-alkanes and those based on $\mathrm{LCOH}$. In the present study the PCA scores based on n-alkanes and on $\mathrm{LCOH}$ were used as the fixed and the fitted values, respectively. Large values of unexplained residual variance after OPR imply that there are large differences between the spatial configurations resulting from PCA on the n-alkanes or on the $\mathrm{LCOH}$. This, in turn, indicates that $n$-alkanes and $\mathrm{LCOH}$ are providing different types of discriminatory information which could be used to differentiate between the plant species involved.

Discriminant Analysis (DA; SPSS Inc., Chicago) was then applied to the n-alkane and $\mathrm{LCOH}$ concentration data in the first 2 data sets in which logical groupings of species were possible (the combined data set $(1+2)$, and data set 1 alone-see below), to assess how effectively defined groups of species could be differentiated using either the n-alkanes alone, or together with the $\mathrm{LCOH}$
Although the species groupings for the combined data set $(1+2)$ are logical from the point of view of likely sward compositions, they do not take into account that plant wax marker concentrations are for leaf blade only in data set 2 and are based on samples collected from spaced plants at a different location from the shoot samples in data set 1 . The conduct of DA with data set 1 alone thus allows a more valid assessment of the capacity to distinguish the defined groups of Lotus spp., clovers and grasses, in shoot samples collected contemporaneously from the same sward.

To perform DA analyses, species/cultivars within a defined group were regarded as replicates, the stepwise method was used and the Mahalanobis distance applied to assess differences between dietary categories (SPSS Inc., Chicago). At each step of the analysis, the variable that maximized the Mahalanobis distance between the 2 closest categories was entered. The minimum partial value of $F$ for the variable to be entered was 3.84 and the maximum partial value of $\mathrm{F}$ for the variable to be removed was 2.71 . The Jack-knife cross-validation procedure was used to assess the proportion of plant species correctly classified into the defined dietary categories (SPSS Inc., Chicago).

Differences among species groupings in DA scores were tested with a multi-way analysis of variance, followed by Scheffé multi-way tests, using the species groupings as the fixed factor and the discriminant scores as the independent variables ( $\mathrm{Zar}$ 1996).

\section{Results}

\section{Concentrations of $\mathbf{n}$-alkanes and long-chain fatty alcohols}

Patterns of alkane concentrations in the species in data sets 1 to 3 (Table 1) were, in general, similar to those in previous reports (Dove and Mayes 1996, Dove et al. 1996), in that odd-chain alkanes were present in higher concentration than evenchain alkanes.

Even-chain long-chain fatty alcohols $(\mathrm{LCOH})$ were detected in higher concentrations than odd-chain $\mathrm{LCOH}$ and in addition, were often an order of magnitude higher than $\mathrm{n}$-alkane concentrations. The LCOH 10-C29-OL was only detected in data set 1 and 1-C27-OL and 1-C28-OL were not detected in data set 3 (Table 2). Legumes tended to have higher concentrations of 1-C30-OL than grasses and, within legumes, 1-C30-OL was detected at high concentrations in clovers and 1-C26-
OL and 1-C28-OL tended to be higher in Lotus spp. (Table 2, data set 1). Concentrations of $\mathrm{LCOH}$ in data set 3 tended to be lower than in data sets 1 and 2. Overall there were large variations in concentrations of even-chain $\mathrm{LCOH}$ among plant species in each data set which may indicate the value of $\mathrm{LCOH}$ as species markers.

\section{Principal Component Analyses and Orthogonal Procrustes Rotation}

Principal Component Analyses, based either on n-alkanes or on $\mathrm{LCOH}$, were conducted for all data sets separately and for all possible combinations of data sets (Table 3). In all of these cases, most of the observed variance in the pattern of plant wax marker concentrations was explained by the first 3 principal components ( $\mathrm{PCl}$ to $\mathrm{PC} 3$ ). When analyses were based on $\mathrm{n}$ alkanes, $\mathrm{PCl}$ to $\mathrm{PC} 3$ explained 86 to $93 \%$ of the variance; $\mathrm{PC} 1$ to $\mathrm{PC} 3$ values for analyses based on the $\mathrm{LCOH}$ were 75 to 99\% (Table 3).

When the 2 sets of PC scores were compared by OPR, 48 to $82 \%$ of the total sums of squares were left unexplained (64 to $82 \%$ within the individual data sets 1 to 3 ; Table 3). This indicates that in all analyses, the $\mathrm{LCOH}$ were contributing discriminatory information additional to that provided by the $\mathrm{n}$-alkanes.

This is examined further in Figures 1 to 3, for the samples of individual plant species in data sets 1 to 3 , respectively. These figures present the plots of $\mathrm{PC} 1$ versus $\mathrm{PC} 2$ in each data set, and indicate 2 things:

(a) the degree of rotation of these axes effected by OPR, in attempting to minimize the residual variation between PC scores based on n-alkanes or on LCOH (solid axes v. dotted axes, respectively) and,

(b) the nature of the scatter of points representing the samples of individual plant species, for both n-alkanes (upper case letters) and $\mathrm{LCOH}$ (lower case italic letters).

For all 3 data sets, it is clear that, despite substantial rotation of the $\mathrm{PCl}$ and PC2 axes, the spatial distribution of the points representing the samples of the different species remains distinct.

\section{Differentiation of groups of species using Discriminant Analyses}

The results of the Principal Component Analysis (PCA) described above identified differences in the patterns of both n-alkane and long-chain fatty alcohol ( $\mathrm{LCOH}$ ) concentrations. Of greater significance for the 


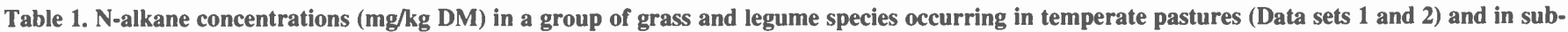
tropical grasses (Data set 3 ) in New South Wales, Australia.

\begin{tabular}{|c|c|c|c|c|c|c|c|c|c|c|}
\hline & $\begin{array}{l}\text { n-Alk } \\
\text { C25 }\end{array}$ & $\mathrm{C} 26$ & $\mathrm{C} 27$ & $\mathrm{C} 28$ & C29 & $\mathrm{C} 30$ & C31 & $\mathrm{C} 32$ & C33 & C35 \\
\hline \multicolumn{11}{|l|}{ Data set 1} \\
\hline \multicolumn{11}{|l|}{ Plant Groups } \\
\hline \multicolumn{11}{|l|}{ Lotus spp. } \\
\hline Lotus corniculatus "Prostrate" & 14.7 & 5.0 & 44.4 & 6.3 & 38.8 & 3.5 & 40.1 & 6.5 & 42.4 & 2.0 \\
\hline Lotus corniculatus cv. Goldie & 14.4 & 4.1 & 37.9 & 5.5 & 37.5 & 2.8 & 34.3 & 5.0 & 33.3 & 0.0 \\
\hline Lotus pedunculatus cv. Sharnae & 23.8 & 6.5 & 237.2 & 15.9 & 384.7 & 5.6 & 49.2 & 3.5 & 19.7 & 0.0 \\
\hline Lotus pedunculatus cv. Maku & 15.0 & 4.5 & 150.9 & 9.7 & 211.7 & 3.6 & 55.0 & 4.1 & 37.3 & 1.2 \\
\hline Average & 17.0 & 5.0 & 117.6 & 9.4 & 168.2 & 3.9 & 44.6 & 4.7 & 33.2 & 0.8 \\
\hline \multicolumn{11}{|l|}{ Grasses } \\
\hline Austrodanthonia richardsonii & 18.6 & 3.0 & 26.4 & 6.6 & 58.5 & 7.3 & 89.6 & 15.0 & 11.0 & 0.0 \\
\hline Phalaris aquatica & 26.7 & 2.6 & 16.9 & 3.7 & 20.8 & 2.6 & 15.8 & 3.5 & 7.3 & 2.3 \\
\hline Vulpia myuros & 27.7 & 3.4 & 40.6 & 9.4 & 175.5 & 19.9 & 183.8 & 9.4 & 37.3 & 2.9 \\
\hline Bromus catharticus & 5.8 & 2.8 & 14.6 & 4.4 & 115.9 & 4.4 & 59.6 & 3.8 & 33.6 & 4.3 \\
\hline Festuca arundinacea & 23.6 & 3.2 & 42.3 & 7.6 & 129.3 & 12.1 & 215.7 & 6.8 & 58.7 & 2.3 \\
\hline Average & 20.5 & 3.0 & 28.1 & 6.3 & 100.0 & 9.3 & 112.9 & 7.7 & 29.6 & 2.4 \\
\hline \multicolumn{11}{|l|}{ Clovers } \\
\hline Trifolium striatum & 10.0 & 4.0 & 48.2 & 30.0 & 989.9 & 22.5 & 68.1 & 5.1 & 7.9 & 0.0 \\
\hline Trifolium glomeratum & 10.7 & 3.1 & 34.9 & 16.3 & 313.5 & 29.7 & 267.0 & 20.5 & 35.9 & 0.0 \\
\hline Trifolium repens & 8.8 & 3.9 & 34.9 & 8.7 & 107.9 & 11.8 & 123.9 & 8.8 & 14.8 & 3.9 \\
\hline Average & 9.8 & 3.6 & 39.3 & 18.3 & 470.4 & 21.3 & 153.0 & 11.5 & 19.6 & 1.3 \\
\hline \multicolumn{11}{|l|}{ Data set 2} \\
\hline Austrodanthonia racemosa & 7.6 & 5.7 & 17.0 & 10.5 & 73.3 & 22.0 & 613.4 & 38.3 & 625.0 & 13.0 \\
\hline Austrodanthonia pilosa & 5.6 & 5.5 & 11.8 & 10.5 & 50.6 & 11.7 & 71.8 & 7.6 & 11.5 & 2.0 \\
\hline Microlaena stipoides 1 & 4.6 & 5.3 & 12.2 & 16.5 & 69.6 & 20.4 & 216.2 & 21.7 & 156.2 & 8.0 \\
\hline Microlaena stipoides 2 & 4.4 & 5.9 & 10.5 & 23.4 & 89.0 & 24.6 & 219.8 & 18.9 & 151.6 & 5.1 \\
\hline Elymus scaber & 6.2 & 3.0 & 11.0 & 4.9 & 51.5 & 5.8 & 95.9 & 5.9 & 36.7 & 4.2 \\
\hline Bothriochloa macra & 22.3 & 15.0 & 132.2 & 11.5 & 64.6 & 14.0 & 111.0 & 10.6 & 33.8 & 4.2 \\
\hline Chloris gayana & 11.6 & 12.1 & 88.6 & 23.8 & 180.1 & 22.8 & 243.3 & 14.7 & 137.5 & 31.8 \\
\hline Themeda australis & 6.9 & 5.6 & 20.4 & 12.1 & 58.9 & 28.1 & 277.8 & 27.6 & 254.9 & 40.9 \\
\hline \multicolumn{11}{|l|}{ Data set 3} \\
\hline Paspalum notatum & 0 & 0 & 0 & 0 & 4.8 & 5 & 35 & 8.1 & 168.4 & 307.8 \\
\hline Paspalum dilatatum & 0 & 0 & 8 & 0 & 12 & 5.1 & 55.8 & 0 & 36.4 & 13.2 \\
\hline Axonopus fissifolius & 0 & 0 & 8.5 & 0 & 25.9 & 7.9 & 118.5 & 15.3 & 222.1 & 93.5 \\
\hline Imperata cylindrica & 0 & 0 & 11.4 & 14 & 48.9 & 47.9 & 206.8 & 35.9 & 153.9 & 36.3 \\
\hline Setaria anceps & 32.2 & 12.6 & 82.2 & 10.1 & 61.9 & 5.8 & 73.5 & 0 & 24.7 & 4.8 \\
\hline Pennisetum clandestinum & 0 & 0 & 6.7 & 0 & 11.5 & 3.9 & 78.5 & 6.7 & 194.5 & 204.3 \\
\hline Cynodon dactylon & 0 & $\mathbf{0}$ & 11.4 & 7.6 & 29.9 & 11.1 & 65.5 & 8.1 & 90.9 & 57.6 \\
\hline Digitaria didactyla & 5.3 & 5.1 & 24.3 & 9.7 & 55.3 & 13.1 & 96.1 & 10.6 & 125.7 & 42.1 \\
\hline Chloris gayana & 4.4 & $\mathbf{0}$ & 20.6 & 6.3 & 31 & 11.9 & 122.8 & 19.3 & 251.7 & 87 \\
\hline Sporobolus indicus cv. major & 0 & 0 & 5.8 & 0 & 11.3 & 11 & 101.5 & 14.1 & 118.2 & 34.6 \\
\hline
\end{tabular}

use of cuticular wax components as markers is the fact that the Orthogonal Procrustes Rotation (OPR) established that the discriminatory information provided by the $\mathrm{LCOH}$ was additional to that provided by the $n$-alkanes. The Discriminant Analyses (DA) were conducted to establish whether the observed differences in the concentration patterns of $n$-alkanes alone, or n-alkanes with $\mathrm{LCOH}$, could be used to differentiate defined groups of species. The grouping of species provided a means of generating replicates within the DA, and a major criterion for defining species groups was that livestock would be likely to encounter them together within a sward. Since it would be most unlikely that animals would encounter the subtropical grasses in data set 3 , growing together with the temperate species in data sets 1 and 2, discriminant analyses were not conducted for data set 3 or any combinations involving it. The DA were thus restricted to the temperate species in data sets 1 and 2 .

Combined data set $(1+2)$ : The defined species groupings when data set 1 and 2 were combined were Lotus spp., clovers, $\mathrm{C}_{3}$ grasses and $\mathrm{C}_{4}$ grasses (Themeda australis, Chloris gayana, Bothriochloa macra). When based on n-alkanes alone (Fig 4-a), the first 2 discriminant scores explained $68.9 \%$ and $23.2 \%$, respectively, of the variance between the defined groups, which were significantly differentiated on both the first (DS1; P $<0.001$ ) and second (DS2; $\mathrm{P}=0.008)$ discriminant axes. Lotus spp. were discriminated from the other species groupings in DS1 ( $\mathrm{P}<$ 0.05 ) and $C_{4}$ grasses similarly differed in DS 1 from $\mathrm{C}_{3}$ grasses and clovers $(\mathrm{P}<$ 0.05). The mean DS1 of clovers and $C_{3}$ grasses did not differ significantly. On DS2, Lotus spp. differed from the $\mathrm{C}_{3}$ and $\mathrm{C}_{4}$ grasses $(\mathrm{P}<0.05)$ but other groups could not be distinguished. Mean scores on the third discriminant axis (DS3) did not differ significantly. Nevertheless, cross-validation procedures indicated that $80 \%$ of individual species were correctly classified, although Lotus corniculatus cv. Goldie, Trifolium repens and Themeda australis were all misclassified as $\mathrm{C}_{3}$ grasses, while Bothriochoa macra was misclassified as a Lotus sp..

When n-alkanes and $\mathrm{LCOH}$ were used together, DS1 and DS2 explained $87.1 \%$ 
Table 2. Long-chain fatty alcohol concentrations (mg/kg DM) in a group of grass and legume species occurring in temperate pastures (Data sets 1 and 2) and in subtropical grasses (Data set 3) in New South Wales, Australia.

\begin{tabular}{|c|c|c|c|c|c|c|c|}
\hline & \multicolumn{2}{|c|}{ Long-chain fatty alcohols } & \multirow[b]{2}{*}{$1-\mathrm{C} 27-\mathrm{OL}$} & \multirow[b]{2}{*}{ 10-C29-OL } & \multirow[b]{2}{*}{ 1-C28-OL } & \multirow[b]{2}{*}{ 1-C29-OL } & \multirow[b]{2}{*}{$1-\mathrm{C} 30-\mathrm{OL}$} \\
\hline & 1-C24-OL & $1-\mathrm{C} 26-\mathrm{OL}$ & & & & & \\
\hline \multicolumn{8}{|l|}{ Data set 1} \\
\hline \multicolumn{8}{|l|}{ Plant groups } \\
\hline \multicolumn{8}{|l|}{ Lotus spp. } \\
\hline Lotus corniculatus "Prostrate" & 20.3 & 1999.5 & 94.4 & 0.0 & 843.5 & 27.5 & 1005.4 \\
\hline Lotus corniculatus cv. Goldie & 12.9 & 2154.4 & 84.0 & 0.0 & 905.0 & 41.1 & 1014.9 \\
\hline Lotus pedunculatus $\mathrm{cv}$. Sharnae & 18.6 & 1378.8 & 81.2 & 13.9 & 844.1 & 63.7 & 785.2 \\
\hline Lotus pedunculatus cv. Maku & 27.8 & 2463.1 & 104.1 & 0.0 & 1327.5 & 42.2 & 1284.8 \\
\hline Average & 19.9 & 1999.0 & 90.9 & 3.5 & 980.0 & 43.6 & 1022.6 \\
\hline \multicolumn{8}{|l|}{ Grasses } \\
\hline Austrodanthonia richardsonii & 65.6 & 435.2 & 24.0 & 0.0 & 170.7 & 42.5 & 130.8 \\
\hline Phalaris aquatica & 18.6 & 3726.1 & 15.0 & 22.7 & 44.7 & 0.0 & 472.0 \\
\hline Vulpia myuros & 79.9 & 900.8 & 17.1 & 12.7 & 42.3 & 30.7 & 64.7 \\
\hline Bromus catharticus & 12.7 & 84.9 & 25.3 & 17.1 & 4052.2 & 36.1 & 83.7 \\
\hline Festuca arundinacea & 26.8 & 638.8 & 21.2 & 10.4 & 100.5 & 17.1 & 58.0 \\
\hline Average & 40.7 & 1157.2 & 20.5 & 12.6 & 882.1 & 25.3 & 161.8 \\
\hline \multicolumn{8}{|l|}{ Clovers } \\
\hline Trifolium striatum & 37.0 & 214.4 & 28.0 & 0.0 & 443.5 & 75.4 & 1259.3 \\
\hline Trifolium glomeratum & 47.7 & 124.4 & 21.0 & 0.0 & 72.9 & 36.8 & 1199.0 \\
\hline Trifolium repens & 18.0 & 142.6 & 18.6 & 0.0 & 61.0 & 27.3 & 1297.3 \\
\hline Average & 34.2 & 160.5 & 22.5 & 0.0 & 192.5 & 46.5 & 1251.9 \\
\hline \multicolumn{8}{|l|}{ Data set 2} \\
\hline Austrodanthonia racemosa & 45.0 & 65.6 & 22.6 & n.d. & 126.1 & 102.5 & 455.4 \\
\hline Austrodanthonia pilosa & 32.6 & 34.9 & 16.6 & n.d. & 24.0 & 88.5 & 556.1 \\
\hline Microlaena stipoides I & 11.4 & 17.0 & 25.7 & n.d. & 35.5 & 169.1 & 1660.3 \\
\hline Microlaena stipoides 2 & 10.0 & 17.0 & 22.7 & n.d. & 50.7 & 233.1 & 3225.9 \\
\hline Elymus scaber & 53.5 & 1868.3 & 19.6 & n.d. & 201.0 & 101.7 & 116.0 \\
\hline Bothriochloa macra & 60.6 & 43.9 & 22.7 & n.d. & 285.4 & 239.8 & 221.0 \\
\hline Chloris gayana & 64.1 & 56.4 & 39.7 & n.d. & 186.8 & 190.1 & 148.5 \\
\hline Themeda australis & 26.4 & 33.2 & 23.3 & n.d. & 14.9 & 112.2 & 68.9 \\
\hline \multicolumn{8}{|l|}{ Data set 3} \\
\hline Paspalum notatum & 31 & 9.2 & n.d. & n.d. & n.d. & 5.1 & 0 \\
\hline Paspalum dilatatum & 41.2 & 15.3 & n.d. & n.d. & n.d. & 268.9 & 20.1 \\
\hline Axonopus fissifolius & 28.4 & 15.5 & n.d. & n.d. & n.d. & 16.7 & 24.2 \\
\hline Imperata cylindrica & 10.8 & 0 & n.d. & n.d. & n.d. & 0 & 0 \\
\hline Setaria anceps & 28 & 20 & n.d. & n.d. & n.d. & 60 & 24.3 \\
\hline Pennisetum clandestinum & 29.7 & 8.7 & n.d. & n.d. & n.d. & 11.4 & 0 \\
\hline Cynodon dactylon & 31.1 & 24.9 & n.d. & n.d. & n.d. & 55.7 & 0 \\
\hline Digitaria didactyla & 88 & 75.6 & n.d. & n.d. & n.d. & 88 & 0 \\
\hline Chloris gayana & 83.9 & 27.9 & n.d. & n.d. & n.d. & 70.9 & 17.3 \\
\hline Sporobolus indicus cv. major & 126.5 & 99.6 & n.d. & n.d. & n.d. & 32.9 & 0 \\
\hline
\end{tabular}

n.d.=not determined

and $10.9 \%$ of the between-group variance, respectively, and species groups were significantly discriminated by DS 1 ( $\mathrm{P}<$ $0.001)$ and DS2 ( $\mathrm{P}<0.001)$. Discrimination on DS3 approached significance $(P<0.10)$. All pairs of species groups were distinguishable on DS1 ( $<<$ 0.05 ) except clovers and $C_{3}$ grasses. On DS2, $C_{4}$ grasses differed significantly from Lotus spp., $\mathrm{C}_{3}$ grasses and clovers ( $\mathrm{P}$ $<0.05$ ). By contrast with DA based on $n-$ alkanes alone, $\mathrm{C}_{3}$ grasses and clovers could be distinguished on DS3 $(\mathrm{P}<0.05$; Fig. 4-b). Cross-validation procedures indicated that $85 \%$ of individual species were correctly classified. Vulpia myuros was misclassified as a clover and Trifolium repens and Themeda australis as $\mathrm{C}_{3}$ grasses.
Data set 1 alone:

In this data set, using n-alkanes significantly differentiated the defined dietary categories along DS1 $(P=0.01)$ but not DS2, although separation approached significance in this axis $(\mathrm{P}=0.054)$. Lotus spp. were significantly differentiated from grasses $(P=0.002)$ and clovers $(P=$ 0.003 ) on DS 1 , but there was no significant difference between grasses and clovers on this axis (Fig. 5-a). The jackknife cross-validation procedures indicated that, based on alkane patterns alone, white clover was misclassified as belonging to the Lotus group (Fig. 5-a).

When n-alkanes were used in conjunction with $\mathrm{LCOH}$, all defined groups were clearly separated with highly significantly differences along both DS1 $(\mathrm{P}<0.0001)$ and DS2 ( $\mathrm{P}<0.0001)$ (Fig. 5-b). All plant species were correctly classified by crossvalidation procedures.

\section{Discussion}

Plant wax n-alkanes have been used successfully for estimating the composition of the herbivore diet in a number of studies (Salt et al. 1994, Fraser and Gordon 1997, Dove et al. 1999, Duncan et al. 1999), but most of these were conducted in field or controlled experiments in which the animals had a limited number of plant species from which to choose. A higher number of markers will be required if there are many plant species to be differentiated in the 
Table 3. Percentage of the variance in the pattern of cuticular wax marker concentration explained by the first 3 principal component scores (PC1 to PC3), following Principal Component Analyses based either on n-alkanes or on long-chain fatty alcohols (LCOH), together with the residual variance left after comparison of the 2 sets of principal component scores by Orthogonal Procrustes Rotation (OPR). Analyses were conducted for each of data sets 1 to 3 and for all possible combinations of data sets.

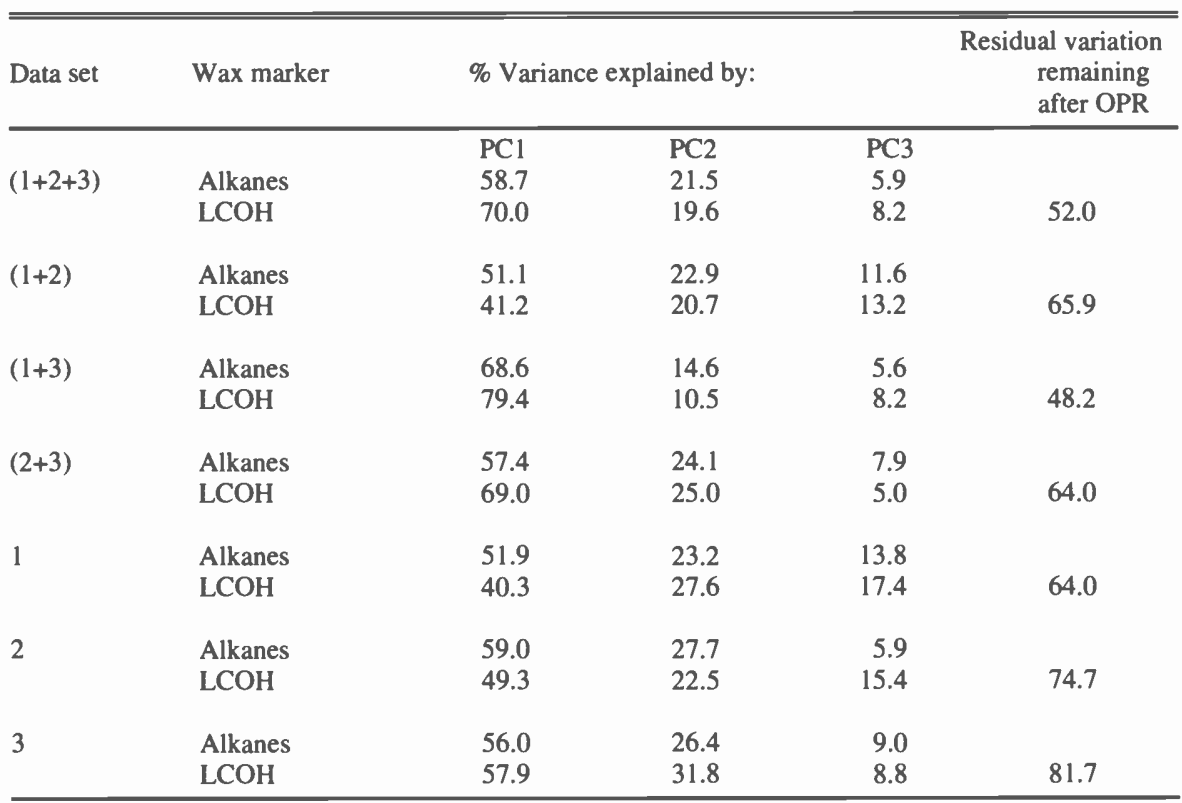

diet. This is frequently the case in studies dealing with free-grazing or wild herbivores feeding on rangelands or more complex plant communities. Theoretically, if the number of components to be differentiated in the diet can be reduced, then a lower number of markers will also be required (Mayes and Dove 2000). Thus, by pooling species into a small number of dietary categories (e.g. grasses, legumes, browse) the number of required markers will be reduced. Such categories, however, must themselves be distinctly characterized by a set of markers. For instance, Dove and Mayes (1991) suggested that legumes and grasses could be differentiated using the C29 and C31 alkanes and, more recently, n-alkanes were successfully used to differentiate the broad categories of browse and grasses in the diet of herbivores (e.g. Pérez-Barbería et al. 1997, Bugalho et al. 2001).

The possibility of differentiating either single plant species or groups of plants in the diet increases if additional markers are available, especially if the additional markers provide different or complementary information about the plant species concerned. This possible differentiation of a wider range of plant species in the diet of the grazing animal requires 2 things in sequence:

(a) the demonstration that, using a marker or markers in the plant wax, individual plant species or groups of species can be distinguished as such,

(b) the demonstration that, after correcting for any loss of marker during transit through the gut of the grazing animal ('fecal recovery'), the fecal marker patterns can be resolved into the intake of individual plant species, using the marker patterns of the plant species.

The present study concentrated on the first of these issues, that is, the potential

Table 4. Contribution of plant species to the variance in estimated concentrations of long-chain alkanes and long-chain fatty alcohols (LCOH) in plant cuticular wax.

\begin{tabular}{|c|c|c|c|}
\hline Source & Plant species type & Alkane/LCOH range & \%variance in alkane concentration due to species \\
\hline $\begin{array}{l}\text { Alkanes } \\
\text { Herbin and Robins (1968) } \\
\text { (recalculated) }\end{array}$ & Agave spp & $\mathrm{C} 26$ to $\mathrm{C} 33$ & $\begin{array}{c}81 \pm 9.76 \text { (all alkanes) } \\
94.9 \pm 2.68 \text { (odd-chain alkanes only) }\end{array}$ \\
\hline $\begin{array}{l}\text { Laredo et al. (1991) } \\
\text { (recalculated) }\end{array}$ & Tropical pasture species & $\mathrm{C} 27$ to $\mathrm{C} 35$ & $80.7 \pm 5.50$ (all alkanes) \\
\hline $\begin{array}{l}\text { Dove and Mayes (1996) } \\
\text { (recalculated) }\end{array}$ & Temperate pasture species & $\mathrm{C} 27$ to $\mathrm{C} 35$ & $81.6 \pm 3.28$ (all alkanes) \\
\hline Dove et al. (1996) & Temperate pasture species & $\mathrm{C} 25$ to $\mathrm{C} 35$ & $85.7 \pm 3.44$ (all alkanes) \\
\hline Chen et al. (1998) & Temperate pasture species & $\mathrm{C} 25$ to $\mathrm{C} 35$ & 87.0 to 93.0 (odd-chain alkanes only) \\
\hline $\begin{array}{l}\text { H.Dove and T.P Bolger } \\
\text { (unpublished) }\end{array}$ & Temperate pasture species & $\mathrm{C} 25$ to $\mathrm{C} 33$ & $\begin{array}{c}87.3 \pm 4.11 \text { (all alkanes) } \\
95.5 \pm 1.01 \text { (odd-chain alkanes only) }\end{array}$ \\
\hline $\begin{array}{l}\text { LCOH } \\
\text { R.W Mayes et al. } \\
\text { (unpublished) }\end{array}$ & $\begin{array}{l}\text { Lolium perenne, Trifolium } \\
\text { repens, Calluna vulgaris, } \\
\text { Vaccinium myrtillus, } \\
\text { Betula pendula, Juncus } \\
\text { effusus }\end{array}$ & $\begin{array}{l}\mathrm{C} 20 \mathrm{OH} \text { to } \mathrm{C} 34 \mathrm{OH} \\
\text { (even-chain only) }\end{array}$ & $\begin{array}{c}62.0 \pm 6.03 \\
67.1 \pm 6.16(\mathrm{C} 20 \mathrm{OH} \text { to } \mathrm{C} 30 \mathrm{OH} \text { only }) \\
\text { (Plant part }=<0.1 \text { to } 21.5 \% \text { of variance })\end{array}$ \\
\hline $\begin{array}{l}\text { H.Dove and T.P.Bolger } \\
\text { (unpublished) }\end{array}$ & Temperate pasture species & $\begin{array}{l}\mathrm{C} 20 \mathrm{OH} \text { to } \mathrm{C} 30 \mathrm{OH} \\
\text { (even-chain only) }\end{array}$ & $82.4 \pm 7.46$ \\
\hline
\end{tabular}




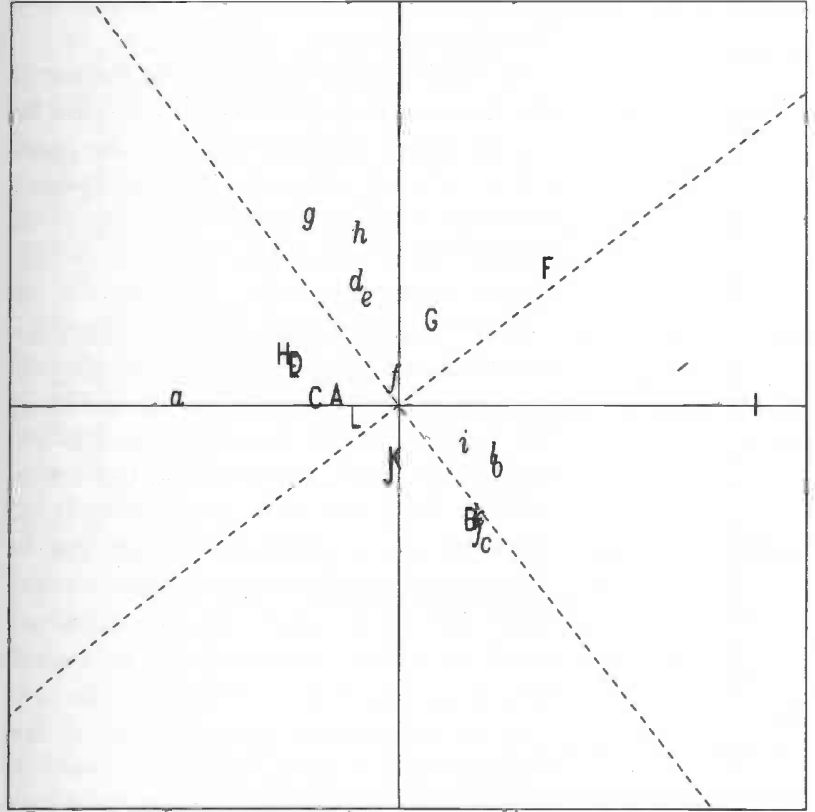

Fig. 1. Graphical representation of the results of Orthogonal Procrustes Rotation (OPR) based on the cuticular wax marker content of the plant species in data set 1 . Upper case letters and solid axes refer to the n-alkanes in the species as listed below, while lower case italic letters and dotted axes refer to long-chain fatty alcohols (LCOH). The residual variance after OPR on the first 3 Principal Component scores following Principal Components Analysis on the alkane and LCOH data is given in Table 4.

A, a Bromus catharticus

B, $b$ Trifolium glomeratum

C, $c$ Austrodanthonia richardsonii

$D, d$ Lotus corniculatus cv. Goldie

E, e L. corniculatus 'Prostrate'

F, $f$ L. pedunculatus cv. Sharnae

G, $g$ L. pedunculatus cv. Maku

$\mathrm{H}, \boldsymbol{h}$ Phalaris aquatica

I, $i \quad T$. striatum

$\mathrm{J}, j \quad$ Festuca arundinacea

$\mathbf{K}, k$ Vulpia myuros

L, $l \quad T$. repens

for differentiation of the species themselves, if more markers are available. In our 3 data sets, the Orthogonal Procrustes Rotation (OPR) results indicated that each class of marker (n-alkanes, LCOH) contributed different discriminatory information. This result is particularly important for it suggests that the combination of the 2 types of marker can, on theoretical grounds, permit discrimination between a greater number of plant species.

Although the results of our Principal Component Analyses (PCA) and OPR have demonstrated that $\mathrm{n}$-alkanes and $\mathrm{LCOH}$ provide different information, they do not in themselves quantify the between-species differences in the patterns of concentrations of these markers, since

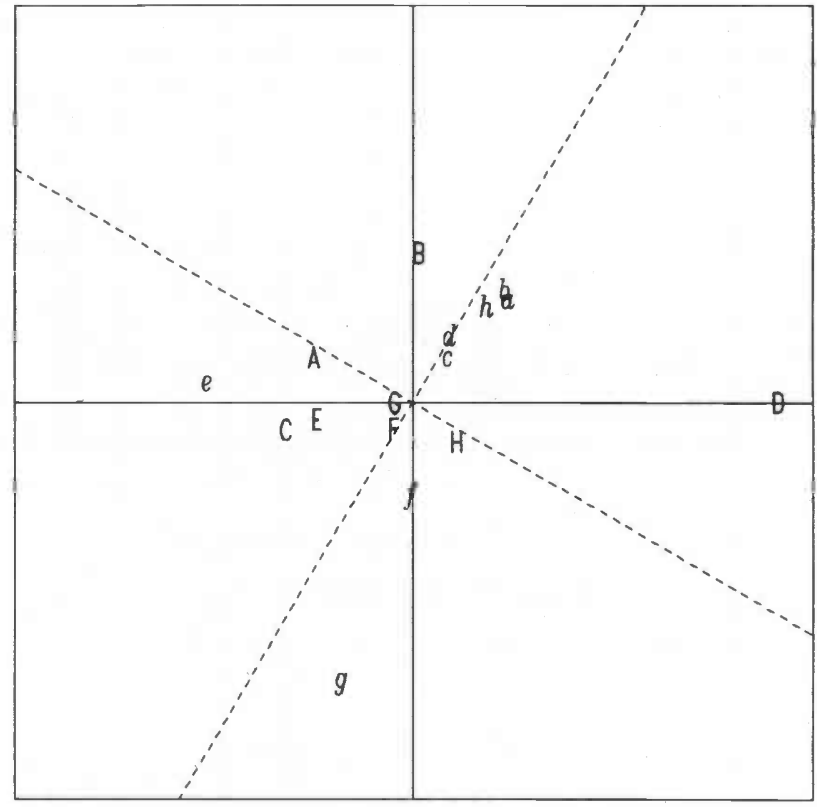

Fig. 2. Graphical representation of the results of Orthogonal Procrustes Rotation (OPR) based on the cuticular wax marker content of the plant species in data set 2 . Upper case letters and solid axes refer to the n-alkanes in the species as listed below, while lower case italic letters and dotted axes refer to long-chain fatty alcohols (LCOH). The residual variance after OPR on the first 3 Principal Component scores following Principal Components Analysis on the alkane and LCOH data is given in Table 4.
A, a Bothriochloa macra
$\mathbf{B}, \boldsymbol{b}$ Chloris gayana
C, c Austrodanthonia pilosa
$\mathrm{D}, \boldsymbol{d}$ Austrodanthonia racemosa
E, e Elymus scaber
F, f Microlaena stipoides 1
$\mathrm{G}, \mathrm{g}$ Microlaena stipoides 2
$\mathrm{H}, \boldsymbol{h}$ Themeda australis

our results were obtained with bulked samples of the species. However, other published reports and unpublished data provide strong evidence that the differentiation evident in Table 3 and Figs 1 to 3 do indeed represent between-species variance. In the data collated and summarised in Table 4, it is clear that in a series of published reports and 1 recent unpublished study, 80 to $95 \%$ of the variance observed in cuticular n-alkane concentrations is attributable to the variance between species. There are no equivalent published data for the $\mathrm{LCOH}$, but in data obtained by 2 of the authors (unpublished data, R.W. Mayes and H. Dove), approximately 65 to $80 \%$ of the observed variance in $\mathrm{LCOH}$ concentrations could be attributable to species. We therefore suggest that the data presented in Table 3 and Figs 1 to 3 of this report do represent between-species differences in marker concentration.

Our results thus suggest that the possibility of differentiating a particular plant species or groups of species can be increased if long-chain fatty alcohols (LCOH) are used as additional markers. Several important issues, however, must be addressed before using more than one class of marker for estimating the composition of the diet of herbivores.

First, if there are large differences in concentration either within or between different classes of marker, such as those obvious in Tables 1 and 2, it is possible that those markers with the highest con- 


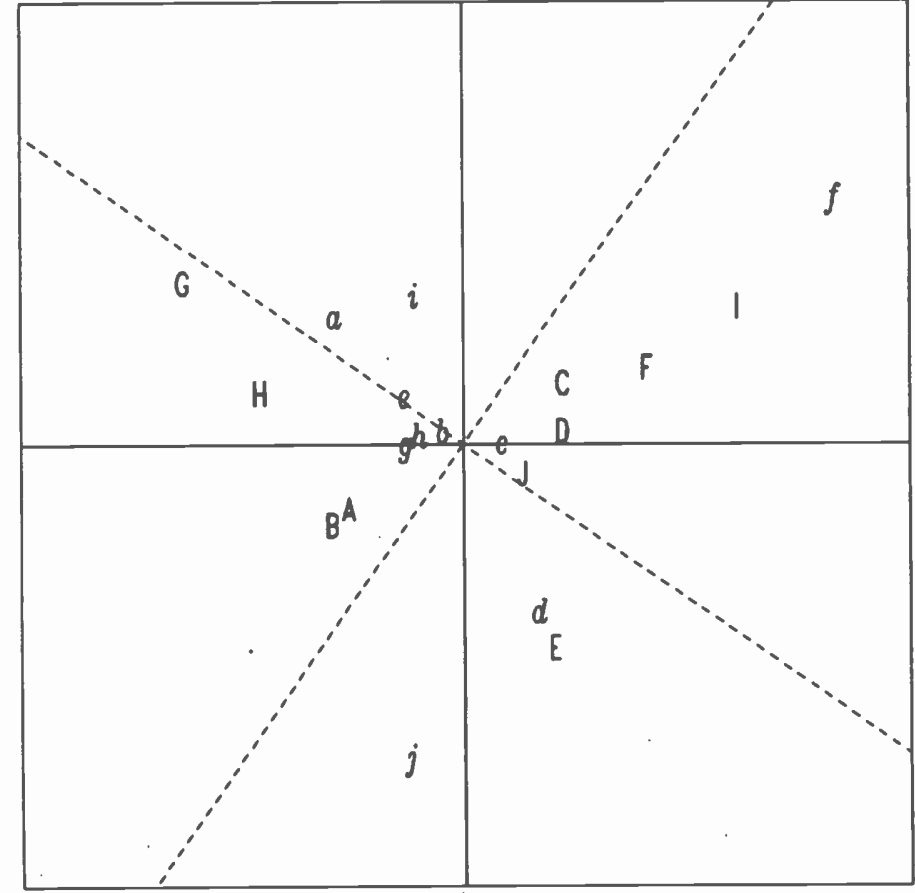

Fig. 3. Graphical representation of the results of Orthogonal Procrustes Rotation (OPR) based on the cuticular wax marker content of the plant species in data set 3 . Upper case letters and solid axes refer to the n-alkanes in the species as listed below, while lower case italic letters and dotted axes refer to long-chain fatty alcohols ( $\mathrm{LCOH}$ ). The residual variance after OPR on the first 3 Principal Component scores following Principal Components Analysis on the alkane and LCOH data is given in Table 4.

A, a Axonopus fissifolius

B, $b$ Chloris gayana

C, c Cynodon dactylon

D, d Digitaria didactyla

$\mathbf{E}, \boldsymbol{e}$ Imperata cylindrica

F, $f$ Paspalum dilatatum

G, $g$ Paspalum notatum

$\mathbf{H}, \boldsymbol{h}$ Pennisetum clandestinum

I, $i \quad$ Setaria anceps

$\mathbf{J}, \mathbf{j}$ Sporobolus indicus $\boldsymbol{v}$. major

centrations will exert undue influence when the markers are used to estimate diet composition. In such cases, particularly if minimization algorithms (Dove and Moore 1995) are used, some form of data scaling or weighting may be required before concentration data are entered into the algorithm. Further work is needed to identify the best scaling procedures to use, in relation to the error structures inherent in the concentration data for the different markers and the nature of the algorithm used to estimate diet composition.

Second, in moving from the differentiation of the plant species themselves to the estimation of the diet composition of the grazing animal, fecal marker concentrations must be adjusted for the possible loss of marker during gut transit. In the case of n-alkanes, it is now well established that fecal recovery of consumed n-alkane is not complete, but increases in curvilinear fashion with increasing carbon-chain length (see Dove and Mayes 1996, Dove and Oliván 1998). For alkane C35 and above, fecal recovery approaches $100 \%$. Data are therefore available for use in correcting fecal n-alkane concentrations for incomplete recovery. The possible use of $\mathrm{LCOH}$ as diet composition markers is a very recent development and there are no published estimates of fecal $\mathrm{LCOH}$ recovery. However, recent data obtained with sheep fed mixed diets (Hafiz Ali, R.W. Mayes and E.R. Ørskov, unpublished data) indicate that, as with the n-alkanes, the fecal recovery of $\mathrm{LCOH}$ is incomplete but increases with carbon-chain length to be essentially complete for 1-C30-OL. By contrast with the n-alkanes, the response appears linear rather than curvilinear. To realize the potential of $\mathrm{LCOH}$ as diet com- position markers, there is an urgent need for more such data.

A further point relates to the number of markers used in the analysis. Whilst the use of more markers increases the possibility of differentiating plant species (Mayes and Dove 2000), using more markers does not always imply better diet composition estimates. This may be the case when using markers that are not distinct for species or groups of plants and, consequently, do not correlate well with the differentiation between possible diet components (see, for example, Dove et al. 1999). To overcome this difficulty, a reduced set of effective markers can be selected by employing multivariate statistical methods such as Discriminant Analysis (DA). Selecting markers using DA, however, requires that replicate samples of the species be available. If diet composition is to be estimated based on individual plant species, then replicate samples of the marker content of each individual species will be required. If diet composition is to be estimated based on defined groups of species, then a number of plant species must be available to function as 'replicates' within each group.

Multivariate statistical tools such as DA are a promising approach for classifying dietary groups. It should be noted that 'statistically meaningful' groups (i.e., formed by plant species similar in their marker content) may not always correspond to taxonomically or nutritionally relevant groups, though this is more likely if just 1 class of marker is used. For instance, when using n-alkanes alone, white clover was grouped with Lotus spp.. Conversely, if diet composition is to be estimated based on defined dietary categories, nutritionally meaningful groups should only be composed of species statistically similar in their marker content. If that condition is not met, then the herbivore's potential feeding selectivity within the dietary group may influence the estimate of diet composition. For instance, this will occur if the herbivore feeds selectively on a particular species in which the pattern of marker concentration deviates substantially from the remaining species within the dietary group (Bugalho et al. 2002). In either case, using both $\mathrm{LCOH}$ and n-alkanes will increase the possibility of defining groups of plants that are relevant both nutritionally and statistically.

In a recent report, Kelman et al. (2003) used some of the plant wax marker concentrations in data set 1 , together with equivalent fecal marker concentrations (adjusted for incomplete fecal recovery), 

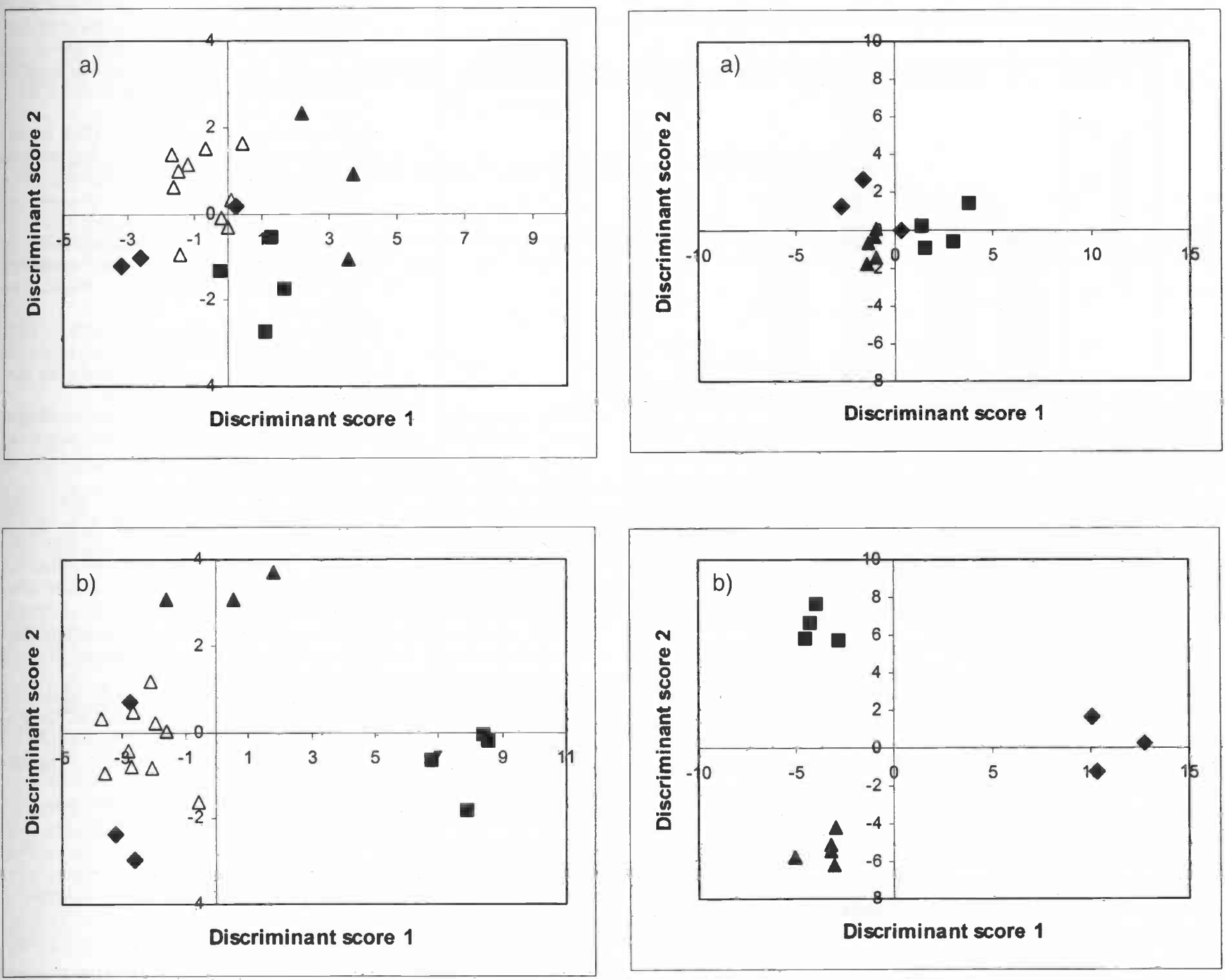

Fig. 4. Discriminant analysis based on the defined categories formed from the plant species in the combined data set $(1+2)$, when using a) n-alkanes alone (variation explained: discriminant score (DS)1 $=68.9 \%$, DS2 $=23.2 \%$ or b) n-alkanes and long-chain fatty alcohols (variation explained: $\mathrm{DS} 1=\mathbf{8 7 . 1 \%}, \mathrm{DS} 2=10.9 \%$ ). Diamonds represent clovers, squares Lotus spp., open triangles $\mathrm{C} 3$ grasses and closed triangles $\mathrm{C} 4$ grasses.

Fig. 5. Discriminant analysis based on the defined categories formed from the plant species in data set $\mathbf{1}$, when using a) $\mathbf{n}$-alkanes alone (variation explained: $\mathrm{DS} 1=81.0 \%, \mathrm{DS} 2=19 \%$ or $\mathrm{b}$ ) $\mathrm{n}$-alkanes and long-chain fatty alcohols (variation explained: DS1 $=61.4 \%$, DS2 $=38.6 \%$ ). Diamonds represent clovers, triangles grasses and squares Lotus spp.; in Fig. 5a, the diamond closest to the squares represents white clover.

to estimate the species composition of the diet of sheep grazing the sward from which the samples in data set 1 were obtained. When based on n-alkane concentrations alone, estimated diet composition indicated a higher proportion of clover in the consumed diet than in the sward (Fig.6). However, this result was possibly compromised by the fact that, based on n-alkanes alone, white clover was often misclassified as a Lotus, in a manner similar to the misclassification described above, for the differentiation of the plant species themselves (Fig. 5-a). Diet compositions were therefore re-esti- mated using n-alkanes and $\mathrm{LCOH}$. This confirmed that dietary clover content was much higher than in the sward (Fig. 6), and also indicated that over $90 \%$ of the Lotus consumed was $L$. corniculatus, the species with lower condensed tannin content. The authors considered these to be reliable estimates of diet composition, because all herbage species were statistically well discriminated by the combination of n-alkanes and LCOH.

\section{Conclusions}

Long-chain fatty alcohols ( $\mathrm{LCOH})$ in plant cuticular wax, used together with nalkanes, allowed a better discrimination between plant species or groups of species than using n-alkanes alone, which shows the potential of using both classes of compounds for estimating the species composition of the diet of herbivores. The $\mathrm{LCOH}$ are widespread in plant cuticles and can be extracted and quantified by an extension of the procedure used for n-alkanes. Using such markers increases the possibility of 


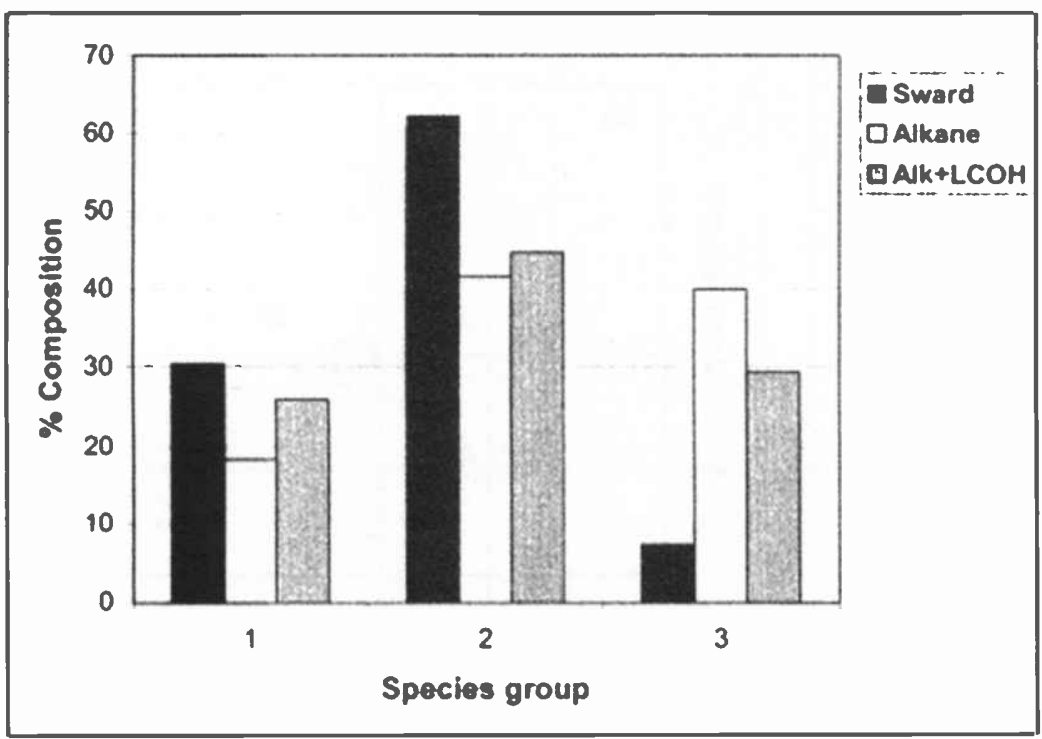

Fig. 6. Comparison of the content of the defined species groups (data set 1 ) in the sward (solid bars), with the species composition of the diet of sheep grazing the sward, estimated either from herbage and fecal n-alkane concentrations (open bars), or these plus herbage and fecal long-chain fatty alcohol (LCOH) concentrations (stippled bars). Species group 1 = Lotus; species group 2 = grasses; species group 3 = clovers. Re-calculated from tabulated data in Kelman et al. (2003).

differentiating species or groups of species in an herbivore's diet, because they contribute discriminatory information additional to the n-alkanes. The combination of n-alkanes and $\mathrm{LCOH}$ was recently used successfully to differentiate grass, clover and Lotus spp. in the diet of grazing sheep (Kelman et al. 2003). Although further validation work is needed, particularly in relation to the estimation of rates of recovery of $\mathrm{LCOH}$ in feces, $\mathrm{LCOH}$ appear to have great potential as additional diet composition markers in studies of herbivore nutrition. Plant wax alkanes and alcohols may complement or be advantageously used with other techniques for estimating diet composition of herbivores (Holecheck et al. 1982).

\section{Literature Cited}

Bugalho, M.N., J.A. Milne, and R.W Mayes. 2002. The effects of feeding selectivity on the estimation of diet composition using the nalkane technique. Grass and Forage Sci. 57:224-231.

Bugalho, M.N., J.A. Milne, and P.A. Racey. 2001. The foraging ecology of red deer (Cervus elaphus) in a Mediterranean environment: is a larger body size advantageous? J. Zool. (London). 255:285-289.

Chen, W., R.D.B. Lefroy, J.M. Scott, and G.J. Blair. 1998. Field variations in n-alkane signatures among plant species in "degraded" and perennial pastures on the Northern Tablelands of New South Wales. Aust. J. Agr. Res. 49:263-268.
Fraser, M. D. and I.J. Gordon. 1997. Organic matter intake, diet digestibility and feeding behaviour of goats, red deer and South American camelids feeding on three contrasting Scottish upland vegetation communities. J. Appl. Ecol. 34:677-698.

Herbin, G.A. and P.A. Robins. 1968. Studies on plant cuticular waxes - II. Alkanes from members of the genus Agave (Agavaceae), the genera Kalanchoe, Echeveria, Crassula and Sedum (Crassulaceae) and the genus Eucalyptus (Myrtaceae) with an examination of Hutchinson's sub-division of the Angiosperms into Herbaceae and Lignosae. Phytochem. 7:257-268.

Hoebee, S.E., H. Dove, and D.I. Officer. 1998. Using plant wax alkanes to estimate the species composition of sub-tropical grass mixtures. Anim. Prod. Aust. 22: 364.

Holechek, J.L., M. Vavra, and R.D. Pieper. 1982. Botanical composition determination of range herbivore diets: A review. J. Range Manage. 35:309-315.

Kelman, W., M. Bugalho, and H. Dove. 2003. Cuticular wax alkanes and alcohols used as markers to estimate diet composition of sheep (Ovis aries). Biochem. Syst. Ecol. 31: 919-927.

Kolattukudy, P.E. 1976. Introduction to natural waxes, p. 1-15 In: P.E. Kolattukudy (Ed.) Chemistry and Biochemistry of Natural Waxes. Elsevier. Amsterdam.

Laredo, M.A., G.D. Simpson, D.J. Minson and C.G. Orpin. 1991. The potential for using nalkanes in tropical forages as a marker for the determination of dry-matter intake by grazing ruminants. J. Agr. Res. 177:355-361

Mayes, R.W. and H. Dove. 2000. Measurement of dietary nutrient intake in free-ranging mammalian herbivores. Nutr. Res. Rev. 13:107-138.

Mayes, R.W., C.S. Lamb, and P.M. Colgrove. 1986. The use of dosed and herbage $n$-alkanes as markers for the determination of herbage intake. J. Agr. Sci. 107: 161-170.

Norton, M.R., D. Garden, C. Waters, R.D.B. Whalley, D. Friend, M. Mitchell, E. Kobelt, G. Auricht, and P. Sanford. 2001. On-farm native and low input grasses network; multisite testing. Final Report on Project TR045, Meat and Livestock Australia. Australia.

Pérez-Barbería, F.J., M. Oliván, K. Osoro, and C. Nores. 1997. Sex, seasonal and spatial differences in the diet of Cantabrian chamois Rupicapra pyrenaica parva. Acta Ther. 42:37-46.

Salt, C.A., R.W. Mayes, and D.A. Elston. 1992. Effects of season, grazing intensity and diet composition on the radiocaesium intake by sheep on re-seeded hill pasture. J. Appl. Ecol. 29:378-387.

Salt, C.A., R.W. Mayes, P.M. Colgrove, and C.S. Lamb. 1994. The effects of season and diet composition on the radiocaesium intake by sheep grazing on heather moorland. J. Appl. Ecol. 31:125-136.

Sandberg, R.E., D.C. Adams, T.J. Klopfenstein, and R.J. Grant. 2000. N-alkane as an internal marker for predicting digestibility of forages. J. Range Manage. 53:159-163

Zar, J.H. 1996. Biostatistical Analysis. Prentice Hall International, Inc. New Jersey. 